\title{
Cross-National Interoperability and Enterprise Architecture
}

\author{
John GØTZE, Peter Engelund CHRISTIANSEN, \\ Rasmus Kirkegaard MORTENSEN, Slawomir PASZKOWSKI \\ Copenhagen Business School, Department of Informatics \\ Howitzvej 60, 4th floor, 2000 Frederiksberg, Denmark \\ e-mail: john@gotzespace.dk,pechristiansen@deloitte.dk,kirkegaard@doek.dk, \\ slawomirpaszkowski@gmail.com
}

Received: September 2008; accepted: June 2009

\begin{abstract}
Interoperability is becoming an area with high focus both at national and cross-national level. This paper presents an assessment of the maturity levels of cross-national interoperability activities within the governmental domain in 13 nations. This analysis includes an assessment of national enterprise architecture programs and national interoperability collaborations, in order to find out whether these serve as important precursors for engaging in cross-national interoperability collaborations. This paper document the importance of national activities as a precursor for engaging in cross-national interoperability collaboration by demonstrating the relation between the maturity of national and cross-national activities.
\end{abstract}

Keywords: interoperability, enterprise architecture, maturity, framework, national, cross-national, technical, semantic, syntactic, organisational interoperability, e-government, European interoperability framework.

\section{Introduction}

The public sector in nation states mainly focus on supporting their national administration structures, and has until recently only engaged in information exchange on an ad-hoc basis in inter-organisational settings (Hjort-Madsen, 2006). To enable a greater convenience for the citizens and the businesses, there is a need for providing composite services triggered from one single event. E.g., if a family with children moves to a new place, it should be possible to take care of all the necessities, in form of change of address, doctor, day care and school, in one e-government electronic service (Dunleavy et al., 2005). Providing those "one-stop-shop" services are considered as challenging, because the public sector is often organised into a vertical division containing national, regional, federal and local authorities, which again are divided into horizontally specific domain areas such as tax, social security and education, with highly heterogeneous services and specialised procedures for the provision of them (Layne and Lee, 2001). Enabling interoperability (IOP), either vertically through the levels of the public sector or horizontally across the domains, seems to be a remarkable challenge for the public sector (Hjort-Madsen and Gøtze, 2004). 
When governments are using information technology and digitalisation as instruments of administrative reform, the claim is that IT has the potential for dramatically changing organisations. This is however almost never backed up by evidence (King and Kraemer, 2003). This view is further elaborated by pointing out that the benefits will not be harvested, if ICT is applied without the necessary organisational change addressing the issues of organisational effectiveness (Andersen, 2006). If ICT is applied in an organisation without optimising the supported processes, it will only support the status quo ante, resulting in a new status quo that might be even harder to change, as ICT now supports and legitimises the not optimised organisational processes (King and Kraemer, 2003). Until a point in time the development of information systems in national public domains has been limited to support single public institutions. The institutions have been developing their own specific work routines as well as information systems, and there have only been made little attempts to support communication and exchanges of data between the systems (Hjort-Madsen and Gøtze, 2004). The absence of collaboration in the public domain results in information systems organized into "stove pipes" and separated "islands of information". In the recent years the tide has changed, and cross agency interoperability has attracted high attention. This is particularly driven by e-government, which is perceived as an enabler for an effective public sector. Though, e-government is not only about the public sector alone, it also has an influence on the interaction of the public sector with the citizens and businesses as well. This challenge of creating interoperability is not a national challenge alone, but a worldwide, cross-national challenge in developing interoperable information systems that spans across several organisations internationally. Therefore, the information systems are not only separated into islands inside the national agencies, nations as a whole can be viewed as separated islands as well. In connection to the difficulties in facilitating interoperability nationally, the nations are believed to be facing a challenge of a considerable size in order to achieve cross-national interoperability (CNIOP), which is driven by globalisation and the internal market of the EU, and the cross-national issues arising thereof.

These issues are investigated through a recent survey ${ }^{1}$, where we have examined the maturity levels of cross-national interoperability activities within the governmental domain in 13 nations. The analysis includes an assessment of national Enterprise Architecture (EA) programs and national interoperability collaborations, based on the assumption that these serve as important precursors for engaging in cross-national interoperability collaborations.

To be able to assess national Enterprise Architecture (EA) programs and national interoperability collaborations we have revised an existing EA maturity model and elaborated a model to measure interoperability collaboration maturity.

\footnotetext{
${ }^{1}$ The survey is fully documented in Mortensen and Paszkowski (2008). All documentation is available at www . easurvey . org.
} 


\section{Enterprise Architecture and Interoperability: A Diversified Forest of Frameworks}

EU has stated interoperability as one of the EU's top priorities in the "i2010 - A European Information Society for growth and employment"-program. EU is aware of the challenges concerning achieving cross-national interoperability, and has therefore formed the "Interoperable Delivery of European e-Government Services to Public Administrations, Businesses and Citizens", IDABC, which has publicised the European Interoperability Framework (EIF) for Pan-European e-Government Services (PEGS). Unfortunately the EIF is just one tree in the highly diversified forest of interoperability frameworks, as many organisations and nations have their own interoperability frameworks as results of their own needs and studies (Peristeras and Tarabanis, 2006). The cross-national interoperability challenge is thereby not only a challenge of information system interoperability, but just as much a challenge in the way interoperability frameworks are compatible with each other, and thereby serve as a vehicle for communication between the involved parties in the cross-national interoperability collaborations.

With the above stated in mind it is evident that interoperability is not merely a technical issue, and therefore might require a holistic approach such as an enterprise architecture program or a comprehensive interoperability collaboration in order to be achieved.

Using local, federal, regional and national EA programs is a way of creating a base for interoperability by explicitly stating the mission, goals, processes and ICT of the organisations, which can be used for both horizontal and vertical integration. Interoperability collaborations can serve the same purpose, but it is a fairly new approach compared to EA programs, and it is believed to be in its infancy as a discipline in e-government.

Whether implicit or explicit, all organisations have an architecture (Doucet et al., 2008). Implicit when mission, goals, processes and the ICT of the organisation are not systematically documented and correlated in a coherent way with no master plan. Explicit as in an EA program, which aims at creating a holistic as-is view and a to-be view of the organisation encompassing both strategic, tactic, operational, business and technical issues and aligning the business and IT organisations. The EA program aims at moving the organisation from its current state (as-is) to its future state (Bernard, 2005).

EA is applied in the governmental domain in several nations (Christiansen, 2006). EA programs have many goals, and they are not solely devoted to achieve interoperability, but in a way, it is exactly still what EA is all about, since it tries to create coherence, compatibility and hence interoperability between mission, goals, processes and ICT in an enterprise. A mature EA program could therefore be a precursor for achieving crossnational interoperability.

Interoperability, as a separate area in the e-governmental domain, has also been examined on several occasions (EIF, 2004; Klischewski, 2004; Park and Ram, 2004), but the focus has mainly been on the initial phases of the problem solving model, namely identification and planning. Therefore, there is no evidence of actions taken by the governments in order to achieve cross-national interoperability.

There are several maturity models for e-government, which all try to address the issues of creating efficiency in the public sector with the support from ICT. Common for 
most of them is that they have integration as a measure for maturity and that increased integration leads to increased complexity (Siau and Long, 2005; Grant and Chau, 2005; Layne and Lee, 2001; Andersen and Henriksen, 2006). Integration of applications and services across governments are relatively more complex and problematic than similar integration in private businesses, as they require cross agency cooperation, which is not necessarily forthcoming or legally permitted (Marche and McNiven, 2003; Grant and Chau, 2005). The budgetary constraints of the agencies have additionally a hampering effect on cross-agency arrangements, which were not anticipated or provided for in the budgetary allocations and mandates (OECD, 2003; Grant and Chau, 2005).

\section{The Emerging Government Enterprise Architecture}

Enterprise Architecture is a plan (Lillehagen and Karslen, 2005), a strategic information base, which can be used as a roadmap to achieve goals (USA federal CIO council, 2001), and a management process for understanding the business (Tuker and Aron, 2005). We define Enterprise Architecture as a systematic approach that organizes and guides design, analysis, planning, and documentation activities in an enterprise.

"Mind the gap, mind the gap" is the warning coming from the speakers at some of the stations in the subway of London. It comes whenever a train arrive at the station platform and it is a warning to train passengers to remind them of the sometimes significant gap between the station platform and the door of the train that just have arrived. It is easy to notice the symbolics of the warning example. The parallel between the station platform in the shape of the well-known and present situation of the organisation, the current view as "as is" is clear. The gap parallels the uncertainty and unknown in moving from one station to another, and finally the train paralleling the moving and managing of the uncertainty in the form of strategies and plans toward the goal, the future view "to be" - as the new station. The message is that the awareness about the significant gap between the enterprise current situation and the goal, is of a particular importance. Especially when wanting to enable the movement of an organisation from one stage in to another, it is essential to understand the different dimensions influencing the changes from the "as-is" to the "tobe". Further it is necessary to manage the enterprise through the changes the organisation will face.

When managing an enterprise's transformation from the as-is stage into the to-be stage, it is essential to be able to measure the enterprise quest for the future view. In this way, the EA maturity measures are giving an indication of both, how far the enterprise has succeeded in the process of establishing, operating and gaining value from the EA, and what the enterprise should be aware of in the current stage, before it will be able to go further.

\section{Enterprise Architecure: Measuring the Success}

The purpose of EA maturity models is not to have a simple classification scheme, which only goal is to observe, whether an enterprise should be categorised into one level or 
another, but rather observing the triggers for moving to a level or another (Andersen and Henriksen, 2006; Heeks, 2006).

Depending on the researchers or practitioners definition of the EA concept, different measures will be used to measure the EA maturity, including effectiveness measures, status measures, measures of different levels within the organisation, specific areas such as the EA documentation and management, the models, definitions, principles and artefacts making up the EA, outcome and output measures (Bernard, 2005). According to IAC (2003) it is furthermore important to estimate the EA program and other aspects such as, how the EA is utilized within the IT governance and the decision making.

As well as the measures differentiates depending on the researchers and practitioners mindset, the number of stages/levels, the specification as well as the objectives of the maturity models also differs. In this way, some of the models in the literature are simply generic models focusing on giving a conceptual knowledge and information about measuring maturity, while others are focused on the practical usefulness and performance of the model enabling benchmarking of the enterprise.

Herzum's EA Maturity Levels (Herzum, 2003), Office of Management and Budget's (OMB) Enterprise Architecture Assessment Framework version 2.2 (OMB, 2007), and the United States Government Accountability Offices's (GAO) Enterprise Architecture Management Maturity Framework (EAMMF, version 1.1) (GAO, 2006) are all designed to measure separated EA maturities, orientated at enterprises placed in the public or in the private sector, but not aimed at measuring maturity level of a nation.

Christiansen (2006) created a maturity framework very suitable for measuring EA maturity at a national level within the public sector. Though, when Christiansen used the model in his study, he only used it as a barometer roughly indicating the maturity levels of governments (Gøtze and Christiansen, 2007). In this study we have revised and elaborated the model. Doing so implies a detailed in-depth analysis of the government activities split up into each of the capabilities identified for clearly outlining the maturities of the governments. To be able to do so, we have added improvements to the model for enabling a more precise and transparent use of it.

The model consists of four levels describing the evolving from initial awareness about EA to a national EA program of "the next generation", including different capabilities related to each level. The levels are: (0) awareness, (1) establishment, (2) operation and (3) value-adding.

The maturity levels are illustrated in Fig. 1 and will be outlined in the following:

- Level 0: Awareness. A government at level 0 is characterised by having acknowledged that establishing a national EA program can be beneficial to the nation. A government at level 0 is aware, and has done some initial thoughts towards an establishment of a national EA program but has no specific plan in action. In relation to the questionnaire, if the respondent is not already having a national EA program, the respondent should at least be planning a national EA program within the next four years.

- Level 1: Establishment. The establishment level is characterised by a government which is being at the early stages of maturity or in the initial stages of establishing a 


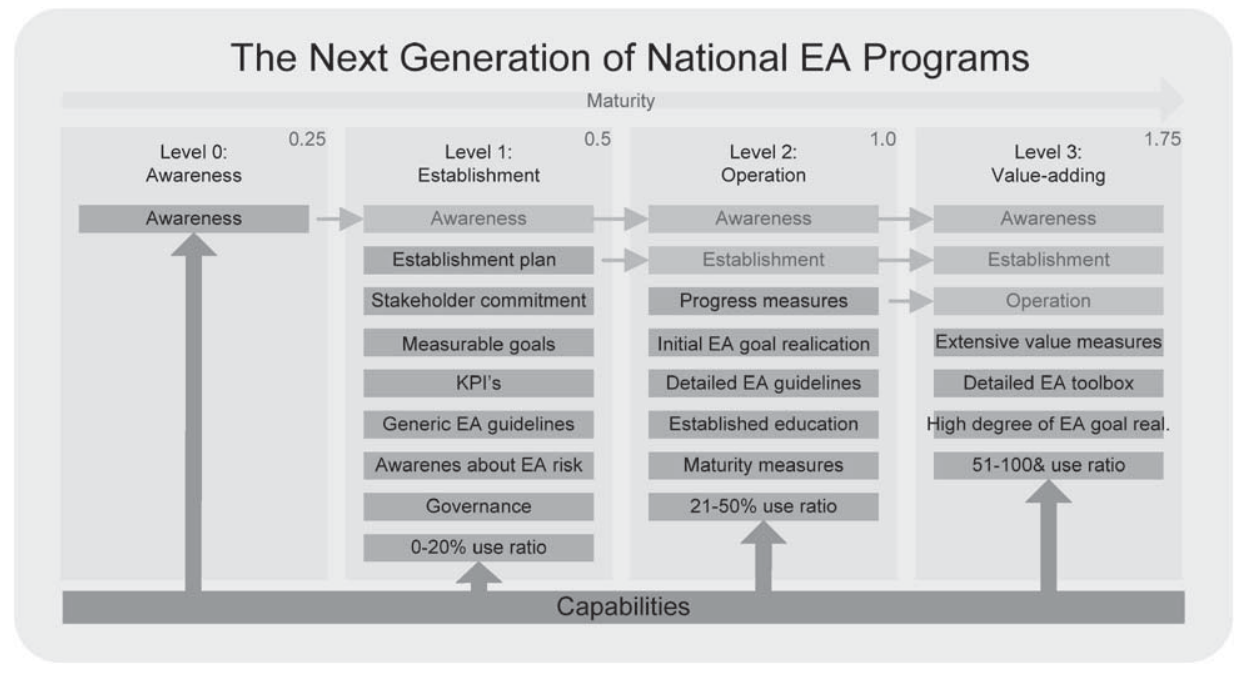

Fig. 1. The next generation of National EA Program.

national EA program. The capabilities at level 1 containing an establishment plan, which identifies whether the government are having a plan for the EA. The identification of stakeholder commitment is also important at this level where indicators as "lack of top management support", "founding" and "political barriers" may give a strong indication of it. Measuring the goals is divided into a two branched tree, one branch focusing on the qualitative goals and the other at the quantitative. It is also at the establishment level that the government have to start using key performance indicators indicating the use of KPIs for measuring the performance. The generic EA guidelines are focusing in whether the government are having guidelines describing the EA. This capability covers both the generic guidelines for the process and the framework as well. It is also at this level the government should be able to recognize any risk related to EA, and they should make suggestions about the governance of the EA and more important, has explicit stated governance guidelines in it. The use ratio is identified to be between $0-20 \%$ of the public entities concerning both the EA process and framework.

Level 2: Operation. A government at level 2 is characterised by finding themselves being based on a fundamental established EA program, with a positive business case and strong stakeholder commitment, because stakeholder expectations has been continually harmonized during the EA program. The level 2 capabilities are better defined and detailed than the capabilities at level 1. Also the use ratio is higher, more specific between $21-50 \%$. Furthermore, the government has established education for training the EA staff. Finally, the progress is being measured and the government should be able to answer questions like "how close/far from are we for realising the goals" and "What is the maturity of the local entities", etc., this giving the government the knowledge to know when the EA is (un)successful. Progress measures and maturity measures may by first glance seems to be one 
of the same kinds. Though, the progress measures are focusing at different goals which not necessarily are a part of the evaluation of the maturity of the government. Level 3: Value-adding. Level 3 is the final level. At this level the government has a high degree of goal realisation, and knows exactly when and why they are creating efficiency as a result of the national EA program. At the value-adding level, the government will be able to answer questions like: "What are the total expenditures of the EA program", "What are the benefits related to the EA program" and "What is the return of investment for the national EA program", which all implies extensive value measures. Governments identified in level 3 have very detailed frameworks, processes, EA specific tools, etc., which all are supporting the realization of the specified goals. At final level, the governments are having a very high use ratio approximating at 51-100\%.

\subsection{Preparing the Model for this Study}

According to the model presented by Christiansen (2006) the model does not enforce that one level should be fulfilled before moving to the next level. In this way, a government will be able to have several of the capabilities within one level meanwhile having some of the capabilities of the next level and so on. Though, in relation to some of the capabilities within the different levels, the nature of the model explicit states that some of the capabilities in previous levels need to be fulfilled before fulfilling the capability of the next level. This is clearly the case of the level one capabilities "KPI's" and "Measurable goals" which both needed to be fulfilled before a government will be able to fulfil the level two capability "Initial EA goal realization". Likewise the latter capability needs to be fulfilled before the level tree capability "High degree of EA goal realization" will ever be possible to be fulfilled. In this way some of the capabilities are interrelated meanwhile others, like the capability "Established education" at level 2, are having no direct relation to the any of the other capabilities.

As improvement of the model, we have changed the use ratio capability at each level, so the use percentages are no longer overlapping each other. Benchmarking of the analysed governments is supported by adding the possibility of allocating the different capabilities different points outlined in the following.

For enabling benchmarking the participating governments' maturity levels with each other, the capabilities within the levels of the "Next Generation of EA Programs" maturity model will be weighted (displayed in the upper right corner of each maturity level). The weightings of the capabilities will reflect the maturity level where the capability is included, the higher maturity level of the capability, the higher score it gets. In this way, for having acknowledged the establishing of a national EA program can be beneficial to the nation in level 0 , will give 0.25 point. For each capability within level 1 it will give 0.5 point. For accomplishing a capability at level 2 it will result in 1 point and finally, accomplishing a capability at level 3 will result in 1.75 point. In this way, if a nation has fulfilled a capability in a higher level, it will be weighted higher, because it is more difficult to accomplish than a capability at a lower level. Though, what is worth mentioning 
is the points allocated to the capabilities at the different maturity levels is only meant for illustrating that a capability at a higher level is likely harder to accomplish than a capability at a lower level, and therefore, the capability should be weighted higher. In the light of this, the considerations concerning the weighting score of each capability are not a result of a mathematic form and no further thoughts, than the above stated, have been allocated at this point. If a government has not acknowledged that establishing a national EA program, it will gain 0 points. The maximum number of points a government will be able to gain is 17.25 by having all the capabilities in all the levels of the model.

EA can be overwhelming to perform due to the all covering nature as it not only aims at creating interoperability. As an alternative approach to achieve interoperability are there several interoperability frameworks gaining foothold in the governmental arena. The concept of interoperability and frameworks for creating it will be described in the following section.

\section{Interoperability in Frameworks}

Interoperability generally implies compatibility of entities, procedures and equipment. Interoperability implies that the software, hardware and procedures in use by two or more entities are compatible, and hence that it is possible to undertake common or related activities.

Interoperability is by the EU perceived as a key bottleneck for ICT efficiency, and pointed out as one of the areas, where further research is needed in order to create solutions that can foster a competitive environment for further growth and employment (i2010). Interoperability receives a great deal of attention in the e-government domain as an enabler for Pan-European e-Government Services.

The focus of the interoperability efforts can be divided in three main categories: administration to administration; administration to business and administration to citizen (Gartner, 2007). The focus depends on the e-government strategy applied and the maturity of the e-government program (Layne and Lee, 2001). Focus can additionally be divided into functional areas as it is the case with policy and service areas in the governmental domain (Tambouris et al., 2007).

Engaging in cross-national interoperability collaborations could have an impact on the national interoperability collaboration as to how the concepts of interoperability are perceived and applied as a consequence of the broad selection of interoperability frameworks to choose from. The applied interoperability frameworks can hence be more or less compatible with each other. As with every project there are cost and benefits. In order to have an indicator on the performance of the collaboration, it is necessary to have an approach to measure on the profitability of the project in terms of cost versus benefits. In order to ensure compliance to the interoperability collaboration some kind of governance is needed. Governance arrangements can take different forms, and be mandated by law or proposed as a practice, among others.

Business drivers can provide motivation for interoperability collaborations and clarify which goals can be targeted and achieved. The main goal of interoperability concerns 
creating vertical and horizontal integration. This integration could both have qualitative and quantitative goals and it could be linked to the e-government strategy in place.

There are several barriers that can emerge and have to be dealt with, before the goals can be achieved, and even before the interoperability collaboration can be initiated. These barriers consist of cultural, political, legal, technical, financial, managerial, language, knowledge and staffing barriers just to name a few. The identified barriers are similar to the barriers of the EA programs, besides that language can be of special importance when the interoperability collaboration is of cross-national character. Furthermore work with national interoperability can be a barrier, if there are no resources left for the crossnational interoperability collaboration. As with EA programs are proper guidelines of tremendous importance, and the absence of those can also be a barrier for the interoperability collaborations.

The interoperability effort is a composition by the interoperability framework applied, the interoperability layers covered and the organisational level where the interoperability effort is applied, as to whether strategic or operational or combined. Operating at a strategic level doesn't automatically imply that the interoperability collaboration is put into operation, as many strategies never materialises in implementations. On the other hand having an operational approach, without linking it to strategy, can have a negative effect on the legitimacy of the interoperability collaboration. It is best to have a combination of both strategic and operational aspects in the approach.

As stated in the interoperability definition, there is indication of different layers of interoperability, containing software, hardware, procedures and entities. These layers of interoperability are a matter of great discussion in both industry and academia spanning from two to eight vertical levels depending on typology (Peristeras and Tarabanis, 2006). As an example Klischewski's typology defines two levels of integration; the European Interoperability Framework (EIF) defines three levels of interoperability; MITRE has no less than two typologies to choose from; DARPA (LISI) operates with a matrix with five levels in one dimension and NATO (NMI) Operates with five levels of interoperability.

The issue of different typologies is addressed by the Connection, Communication, Consolidation, Collaboration Interoperability Framework (C4IF) (Peristeras and Tarabanis, 2006) cf. Fig. 2.

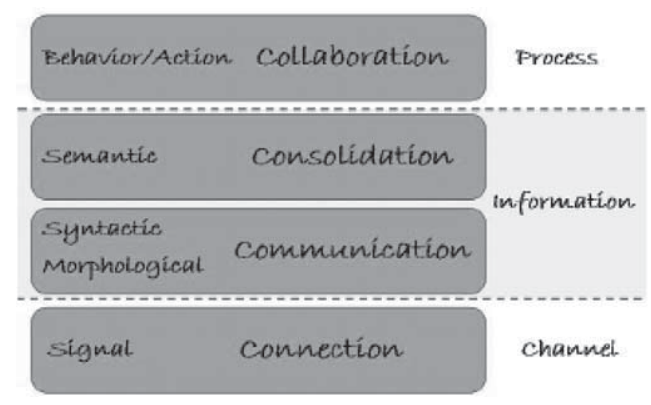

Fig. 2. The levels of the C4IF framework (Peristeras and Tarabanis, 2006). 


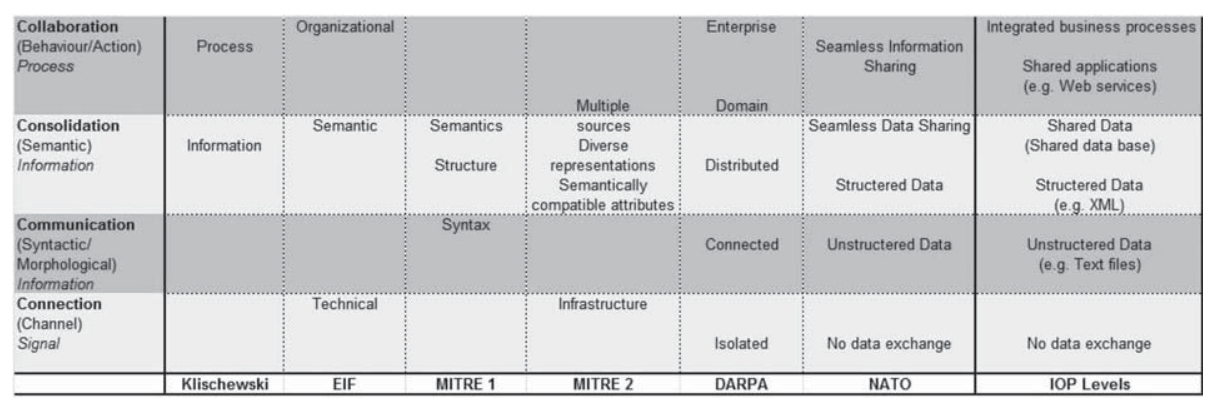

Fig. 3. Mapping the interoperability typologies to the C4IF (inspired by Peristeras and Tarabanis (2006)).

The C4IF framework is a result of a literature study producing a synthesis employing a metaphor from linguistic outlining different types of information system interoperability. The issue of typology incompatibility is addressed by categorising the different interoperability levels of one typology to the connection, communication, consolidation or collaboration levels. Regardless of the amount of levels and the scope of the interoperability typology the typologies can be related to each other through the use of the C4IF framework, as all IOP typologies can find a place in it.

The C4IF framework is trying to map all the above stated typologies in to the four C levels. The mapping for the above mentioned typologies is shown in Fig. 3.

The mapping of the selected typologies enables the comparison of the typologies to each other and to the C4IF framework. This can be practical, when two entities, having different typologies, work together on a project. In order to be able to evaluate the level of interoperability, we have produced the following list of interoperability maturity status levels spanning the above shown frameworks: (0) no data exchange; (1) exchange of unstructured data (e.g., text files); (2) exchange of structured data (e.g., XML); (3) shared data (e.g., Shared data base); (4) shared applications (e.g., web services) and (5) integrated business processes as depicted in the last column of Fig. 3. This high level of granularity should enable the ability to determine the level of achieved interoperability, regardless of interoperability framework applied and the ability to place it in any of them for comparison. The interoperability maturity status levels are a part of the overall interoperability collaboration maturity and relate directly to the level of information system interoperability.

\subsection{Interoperability Collaboration Maturity: Measuring the Success}

Interoperability frameworks are implying the use of different parameters for measuring the status of interoperability with accordance with the interoperability layers suggested by the given framework. This is a good way to measure the actual state of interoperability, but is lacking the context in which interoperability activities are conducted. In a similar way as the EA maturity framework, an interoperability collaboration maturity framework will provide some indicators on the interoperability activities, based on the dimensions presented including motivation, barriers, goals, approach, focus, impact, measurement 
and governance. As a part of this study we have elaborated a simple maturity model to be able to measure the interoperability collaboration maturity based on a range of endogenous and exogenous parameters. The model consists of four levels describing the evolvement from initial awareness about interoperability to interoperability collaborations being value adding. The levels are: (0) awareness, (1) establishment, (2) operation and (3) value-adding.

The maturity levels and the related elements are illustrated in Fig. 4, and will be outlined in the following section.

- Level 0: Awareness. A government at level 0 is characterised by having acknowledged that establishing interoperability collaboration can be beneficial. A government at level 0 is aware, and have done some initial thoughts towards an establishment of interoperability collaboration but has no specific plan in action.

- Level 1: Establishment. The establishment level is characterised by a government which is being at the early stages of maturity or in the initial stages of establishing an interoperability collaboration. The capabilities at level 1 of the interoperability collaboration are: stakeholder commitment, clear goals, key performance indicators (KPI), generic interoperability guidelines, awareness about risks in relation to the interoperability collaboration and a governance structure. The interoperability collaboration will be characterised with a narrow focus on a few policy areas and a narrow focus towards the administration, business or citizen area. The aspects covered by the interoperability collaboration will be few and not spanning all the interoperability layers, furthermore the interoperability collaboration will be at a strategic level. The interoperability status level will in this early stage of the maturity be $0-1$, meaning that there are only exchanges of unstructured data, if there are any exchanges at all.

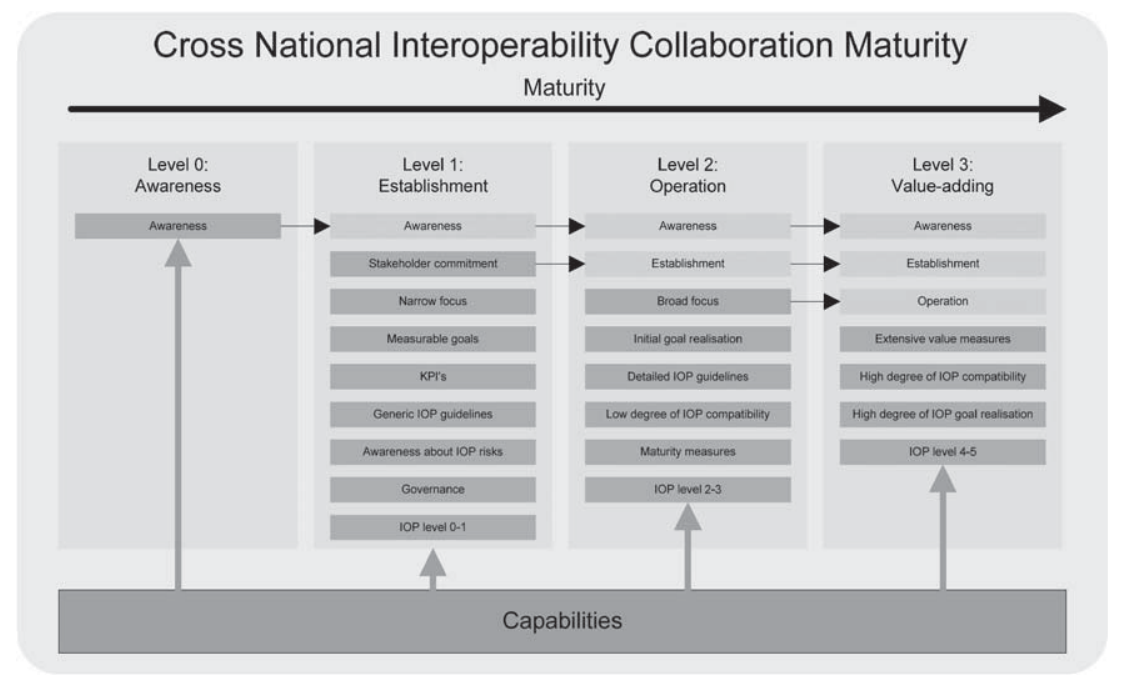

Fig. 4. Cross-national interoperability collaboration maturity model. 
- Level 2: Operation. A government at level 2 is characterised by finding themselves being based on a fundamentally established interoperability collaboration, with a positive business case and strong stakeholder commitment, because stakeholder expectations has been continually harmonized during the interoperability collaboration. The level 2 capabilities are better defined and detailed than the capabilities at level 1. Finally, the progress is being measured and the government should be able to answer questions like "how close/far from are we for realising the goals", etc., this giving the government the knowledge to know when the interoperability collaboration is (un)successful. The interoperability collaboration will be characterised with a broad focus on policy areas and a broad focus towards the administration, business and citizen area. The aspects covered by the interoperability collaboration will be extensive and spanning all the interoperability layers. At this stage will there be exchanges of structured data of, e.g., XML or maybe even shared data in form of a common database.

- Level 3: Value-adding. Level 3 is the final level. At this level the government has a high degree of goal realisation, and knows exactly when and why they are creating value as a result of the interoperability collaboration. At the value-adding level, the government will be able to answer questions like: "What are the total expenditures of the interoperability collaboration", "What are the benefits related to the interoperability collaboration" and "What is the return of investment for the interoperability collaboration". Governments identified in level 3 will have shared applications, e.g., Web services and integrated business processes.

\section{Mapping EA and Interoperability}

EA and interoperability have some similarities, but also some differences. The main similarities reside in the all encompassing nature of both approaches, trying to provide a link between the organisational and the technical aspects. Both approaches use some of the same terms like: organisation, process and data. As a consequence of the similarities between the terms, used by both approaches, we will map the EA architecture levels into the C4IF framework and thereby enable the mapping of EA frameworks to interoperability frameworks.

The main difference in the two approaches is that modern EA programs have both detailed guidelines concerning framework and approach, whilst interoperability focuses mainly focuses on frameworks. Furthermore in the EA frameworks the levels are further divided in how, where, who, when and why besides the what, which is the main focus of the outlined interoperability frameworks.

\section{National EA and Interoperability Survey Results}

A thorough data collection process has been carried out, in order to gather the data used in the analysis. The data gathering process started in November 2007 and ended in April 2008. The participating governments and their representative bodies are summarised in Table 1. 


\begin{tabular}{cc}
\hline C4IF & EA \\
\hline Colllaboration & Bussiness Architecture \\
(Behaviour action) & (Contextual \& conceptual) \\
Process & Strategy, goals, processes \\
Consolodation & Information Architecture \\
(Semantic) & (Logical) \\
Information & System landscape and use cases \\
Connection & Technical Architecture \\
(Channel) & (Physical) \\
Signal & Operating environment \\
\hline
\end{tabular}

Fig. 5. Mapping EA to interoperability.

Table 1

The participating governments

\begin{tabular}{|c|c|c|}
\hline Government & Answering organisation & Responsible ministry \\
\hline Belgium & FEDICT & \\
\hline Canada & Treasury Board, Secretariat & The Treasury Board Secretariat (TBS) \\
\hline Cyprus & $\begin{array}{l}\text { Department of Information Technology } \\
\text { Services }\end{array}$ & $\begin{array}{l}\text { Ministry of Finance, Department of Infor- } \\
\text { mation Technology Services (DITS) }\end{array}$ \\
\hline Denmark & $\begin{array}{l}\text { Ministry of Science, Technology and Inno- } \\
\text { vation - National It - and Telecom Agency }\end{array}$ & \\
\hline Estonia & $\begin{array}{l}\text { Ministry of Economic Affairs and Com- } \\
\text { munications }\end{array}$ & $\begin{array}{l}\text { Ministry of Economic Affairs and Com- } \\
\text { munications }\end{array}$ \\
\hline Finland & $\begin{array}{l}\text { State IT-Management Unit, Ministry of Fi- } \\
\text { nance }\end{array}$ & Ministry of Finance \\
\hline Liechtenstein & $\begin{array}{l}\text { Information Technology Service Office of } \\
\text { Human And Administration Resources, } \\
\text { National Public Administration of LI }\end{array}$ & \\
\hline Netherlands & ICTU & \\
\hline New Zealand & State Services Commission & State Services Commission - ICT Branch \\
\hline Norway & & $\begin{array}{l}\text { Ministry of Government Administration } \\
\text { and Reform }\end{array}$ \\
\hline Poland & $\begin{array}{l}\text { MSWiA (Ministry of Interior and Admin- } \\
\text { istration) }\end{array}$ & MSWiA \\
\hline Sweden & Verva & Finance \\
\hline Turkey & State Planning Organization & $\begin{array}{l}\text { State Planning Organization affiliated to } \\
\text { Prime Ministry }\end{array}$ \\
\hline
\end{tabular}

\subsection{EA Activities}

Most of the participating governments (62\%) have a national EA program. Summarizing the positive responses and the expressions concerning plans of establishing a national EA program within the next three years summarizes to $77 \%$ of the governments, which 
indicate that the participating governments have a high focus on EA on the national level. Belgium, Lichtenstein, Norway, Turkey and Sweden have no national EA program at the moment. $23 \%$ of the governments have no plans of establishing a national EA program in the future.

The governments indicating to have EA programs on a national level are: Netherlands, New Zealand, Poland, Denmark, Estonia, Cyprus, Canada and Finland. Norway has an EA program at a municipal/local level. Belgium has an EA program at a department level and Sweden has an EA program at agency level. None of the three have EA programs at a national level. Belgium and Turkey are planning a national EA program within three years and one year, respectively. Lichtenstein, Norway and Sweden are not planning any national EA programs.

For each of the nations, we scored the capabilities and assessed the maturity level. As an example, Canada's results are shown in Fig. 6. They have setup qualitative as well as quantitative goals, which in the case of the qualitative goals; they are using tools and techniques which are rolled out into management processes resulting in better understanding of programs, projects and investments, etc. Canada has publicized guidelines describing the EA process and framework. In relation to the EA aspects, Canada has described the architectures at different levels. The Business architecture is described at whole $75-100 \%$ in the public sector, meanwhile the information architecture is described at $25-50 \%$, and finally the application and technical architecture are both described at 50-75\% in the public sector. Canada is stating that between 10 and $25 \%$ of the public entities are using the publicized guidelines. Canada is categorised to be at maturity level 2 and has gained 7.25 points for their capabilities.

The analysis of the governments maturity levels, and the points scored for fulfilling the capabilities of the maturity model in the area of national EA are summarised in Table 2.

After outlining the maturity levels of the participating governments it is clear that the governments are positioned in different levels. Compared to the "Next Generation EA Program" it is clear that most of the governments have a lot of work to do, before they will be able to raise their maturity to a higher level.

\section{National EA Program: Canada}

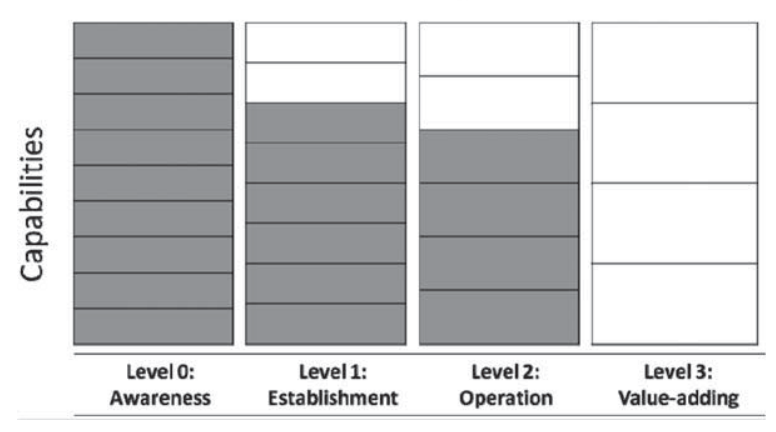

Fig. 6. National EA program maturity Canada. 
Table 2

The participating governments' EA maturity levels and capability score

\begin{tabular}{lcc}
\hline Country & Maturity level & Score \\
\hline Belgium & 1 & 3.5 \\
Canada & 2 & 7.25 \\
Cyprus & 3 & 15.75 \\
Denmark & 2 & 9.5 \\
Estonia & 2 & 10.75 \\
Finland & 2 & 9.25 \\
Liechtenstein & 1 & 0.75 \\
Netherlands & 2 & 6.5 \\
New Zealand & 2 & 6.5 \\
Norway & 0 & 0.25 \\
Poland & 2 & 6.75 \\
Sweden & 1 & 2 \\
Turkey & 1 & 1.75 \\
\hline
\end{tabular}

The Fig. 7 indicates a two partitioning of the participating governments, when disregarding the top performer Cyprus. Norway, Liechtenstein, Turkey, Sweden as well as Belgium are all placed in level 0 or 1 . In general they are lacking capabilities such as measurable goals, key performance indicators as well as stakeholder commitment before they will reach the operational level. In general, the governments placed at the operational level, have accomplished those capabilities and therefore they are capable of initial EA goal realisation, starting measuring the progress. Before they will be able of accomplishing the capabilities at the value-adding level, it is essential for them to have extensive value measures, high degree of EA goal realisation as well as increase the use ratio for how many of the public entities that are using the publicized guidelines.

One government worth a notice is Cyprus. Cyprus has, based on the conducted survey, most of the capabilities needed to accomplish almost all the maturity levels of the "Next Generation of EA Program". Also Norway is worth a notice. Before the completion of the survey, we expected Norway to be one of the governments well positioned in an EA program, but the survey reveal them to just getting awareness about the benefits of an EA program.

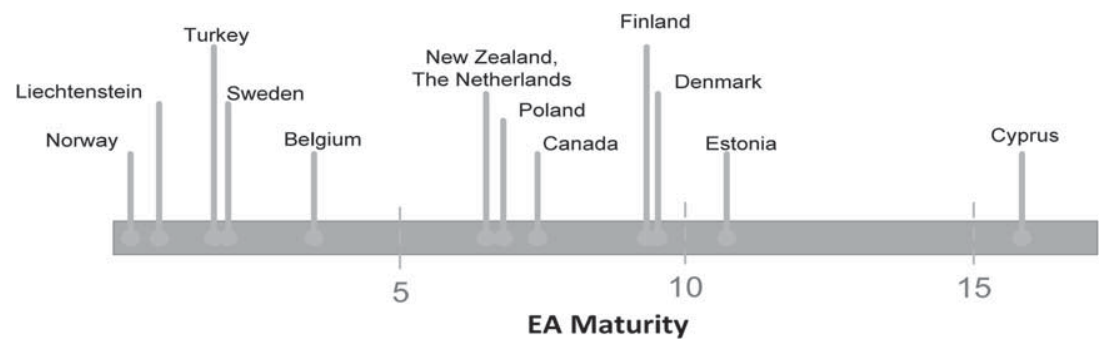

Fig. 7. The participating governments' EA maturity scores. 


\subsection{National Interoperability Activities}

$75 \%$ of the respondents report that they have national interoperability collaborations. Most of the respondents use the EIF as a base for their national interoperability collaboration. Zachman and the UK eGIF are also used as a formal base. $67 \%$ of the respondents report that the level of customisation of the formal base is medium, while $16 \%$ report to have a low degree of customisation and $17 \%$ has a high level of customisation of the formal base.

Answering the question concerning which frameworks are used nationally, can be done in several ways depending on the line drawn as to what qualifies as an interoperability framework. One could make a distinction between EA and interoperability frameworks, but such a distinction is probably too narrow in its scope, as both types of frameworks can be used to achieve interoperability. This assumption is underlined by the survey results concerning business drivers for EA programs, where cross-governmental interoperability was ranked as the most important business driver. Furthermore is the ability to better align business and IT organizations ranked as second in the same category. As both mentioned business drivers for EA programs leads to solving issues of interoperability, it is then relevant to consider EA frameworks as interoperability frameworks. Additionally one of the respondents has stated that they perceive the EA and interoperability frameworks as almost the same.

Different frameworks are reported to be in use in EA programs, of which none qualifies as a formal EA framework. All the frameworks in use are reported to be locally defined and based on EAF, E2AF, EAG, Cap Gemini's IAF and naturally Zachman, which the latter probably had an impact on all of the mentioned frameworks. The level of the formal base in the locally defined frameworks is medium to high, which means that the frameworks are relatively recognizable for the ones familiar with the formal base.

The conceptual and logical abstraction levels are supported by the EA framework of all the respondents. Canada, Denmark and Finland report to support the physical abstraction level in their EA framework.

Business, information and application architecture aspects are covered by all the respondents in their EA framework. Canada, Denmark, Estonia and Finland report to additionally cover the technical architecture aspect in their EA framework. Finland's EA framework covers aspects such as security and integration as well.

The pure interoperability frameworks reported to be used as a formal base nationally are the EIF, UK eGif and Zachman. $67 \%$ of the respondents report that the level of customisation of the formal base is medium. There is a clear preference of the EIF in the European countries.

All the respondents report to be operating with the technical level in their interoperability collaboration. Most of them operate with the semantic and the organisational level. One of the respondents report to be operating with the syntactic level, while another with the legal level in their national interoperability collaboration. The amount of interoperability levels in the national interoperability collaborations range from one to four. 
The above shows that there is a wide range of interoperability frameworks in use by the respondents. The amount of levels of the interoperability frameworks differs from one to four. The distinction between interoperability levels is somehow unclear as there are five different levels in use by the respondents: organizational, semantic, syntactic, technical and legal. As this is only at the national level there are no issues concerning cross-national interoperability collaborations at first glance.

\subsection{Cross-National Interoperability Activities}

$58 \%$ of the respondents report to be having cross-national interoperability collaboration with other countries. Of the respondents not having a cross-national interoperability collaboration one $(20 \%)$ is planning to establish one within a year, three $(60 \%)$ are planning one within two years and one $(20 \%)$ is not planning any cross-national interoperability collaboration at all.

The interest lies on frameworks being used in cross-national collaborations and most of the above mentioned frameworks are not reported as being applied in cross-national interoperability collaborations. Only the EIF and the IDABC Architecture Guidelines are in use in the cross-national interoperability collaborations. Most of the European respondents state that their cross-national interoperability collaborations are aimed at the EU countries through IDABC, but not all seems to be directly engaging in cross-national interoperability collaborations at member state level. UN is stated as global interoperability collaboration by one of the non-European respondents, which also states that the crossnational interoperability collaboration is conducted with all relevant countries and driven by business demands of the policy area at agency level.

All the respondents report to be operating with the technical level in their crossnational interoperability collaboration. Most of them operate with the semantic and the organisational level. One of the respondents reports to be operating with the legal level in their cross-national interoperability collaboration. The amount of interoperability levels in the cross-national interoperability collaborations range from one to four. There is again an unclear distinction between interoperability levels as there are four different levels in use by the respondents: organizational, semantic, technical and legal and they are not all used by all the respondents. The unclear distinction between interoperability levels and the use of them could lead to cross-national interoperability collaborations having a hard time establishing a common formal base. This should especially be viewed in the light of that all the respondents, answering this group of questions, have stated the EIF as their formal base.

Another emerging issue concerns the impact of the cross-national interoperability collaboration on the national interoperability collaboration. $43 \%$ of the respondents report that the cross-national interoperability collaboration has a substantial impact on their national interoperability collaboration. 29\% report that the impact is medium. $14 \%$ report that the impact is low and $14 \%$ report that there is no impact of the cross-national interoperability collaboration on their national interoperability collaboration. The difference between high and low impact may lay in the compatibility of the two collaborations. 57\% 
reports that there is a high level of compatibility of the cross-national interoperability collaboration with the national interoperability collaboration. Three groups of respondents accounting for $14 \%$ each, report the level of compatibility to be very high, low or none. The correlation between impact and compatibility shows that low impact leads to low compatibility and vice versa. This is an issue that could lead to double work as the national and cross-national interoperability collaborations could drift in different directions and require an unnecessary amount of resources in their lifecycles. This is exactly the kind of issues interoperability collaborations should be solving and not creating.

\subsection{Interoperability Maturity}

As in the EA maturity section, the following section will include an analysis of one of the participating government's cross-national interoperability maturity, which will be evaluated according to the capabilities in the maturity stages of the Cross-National Interoperability Collaboration Maturity Model.

Fig. 8 shows an example of the assessment, here for the Netherlands. They have identified no barriers in establishing the collaboration. EIF is used as the cross-national interoperability collaboration framework without any customisation. The Netherlands has stated several business drivers for the collaboration where cross-governmental interoperability is the most important driver. The Netherlands reports to have qualitative goals related to the EU goals in order to support the Pan-European delivery of electronic government services, but so far the Netherlands has achieved no benefits, likewise no measurements of cost or cost to benefit ratio are identified and they have stated no suggested approaches for measuring the cross-national interoperability collaboration status. The governance of the cross-national interoperability collaboration is proposed as a practice. The Netherlands is categorised to be mainly in level 2 and has gained 8.5 points for the capabilities.

The analyses of the governments maturity levels, and the points scored for fulfilling the capabilities of the maturity model in the area of national interoperability and crossnational interoperability collaborations are summarised in Table 3.

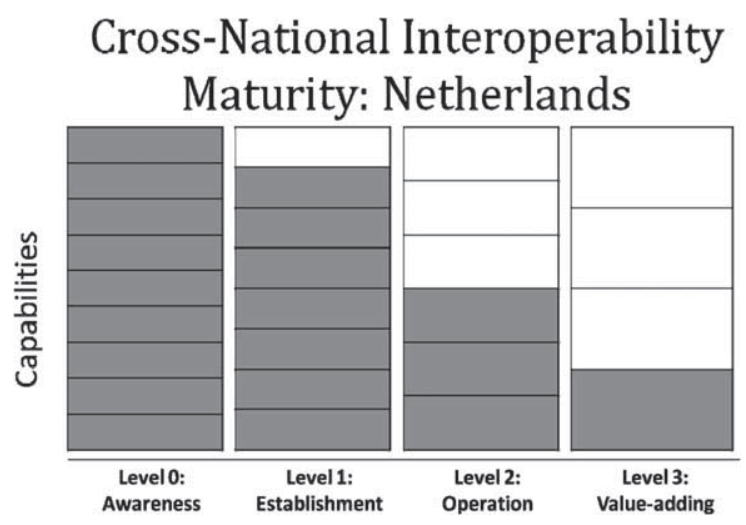

Fig. 8. The Netherlands cross-national interoperability collaboration maturity. 
Table 3

The governments' interoperability collaboration maturity levels and point gained

\begin{tabular}{lccl}
\hline Government & $\begin{array}{c}\text { National interoperability } \\
\text { maturity level }\end{array}$ & $\begin{array}{c}\text { Cross-national interoperability } \\
\text { maturity level }\end{array}$ & Score \\
\hline Belgium & 2 & 1 & 1.25 \\
Canada & 1 & 1 & 2.25 \\
Cyprus & 1 & 2 & 8.5 \\
Denmark & 2 & 2 & 4.25 \\
Estonia & 2 & 2 & 9.25 \\
Finland & 2 & 2 & 4.25 \\
Liechtenstein & 0 & 0 & 0 \\
Netherlands & 2 & 2 & 8.5 \\
New Zealand & 2 & 2 & 7.25 \\
Norway & 0 & 0 & 0 \\
Poland & 1 & 0 & 1 \\
Sweden & 2 & 2 & 7.25 \\
Turkey & 2 & 2 & 4.25 \\
\hline
\end{tabular}

After outlining the maturity levels for the cross-national interoperability for the participating governments it is clear that, like in the case of the national EA programs, the governments are positioned in the initial phases of level 2. Compared to the Cross-National Interoperability Collaboration Maturity model it is clear that most of the governments have a lot of work to do, before they will ever be able to raise the maturity levels into the value adding level.

It appears from Fig. 9, that there basically is a two partitioning of the governments' cross-national interoperability collaboration maturity levels. In general, the governments placed in level 1 are all lacking key performance indicators, detailed interoperability guidelines, and maturity measures as well as getting the stakeholder commitment to the cross-national interoperability collaborations, capabilities that needed to be accomplished before they ever will be capable of having progress. In relation to the governments placed

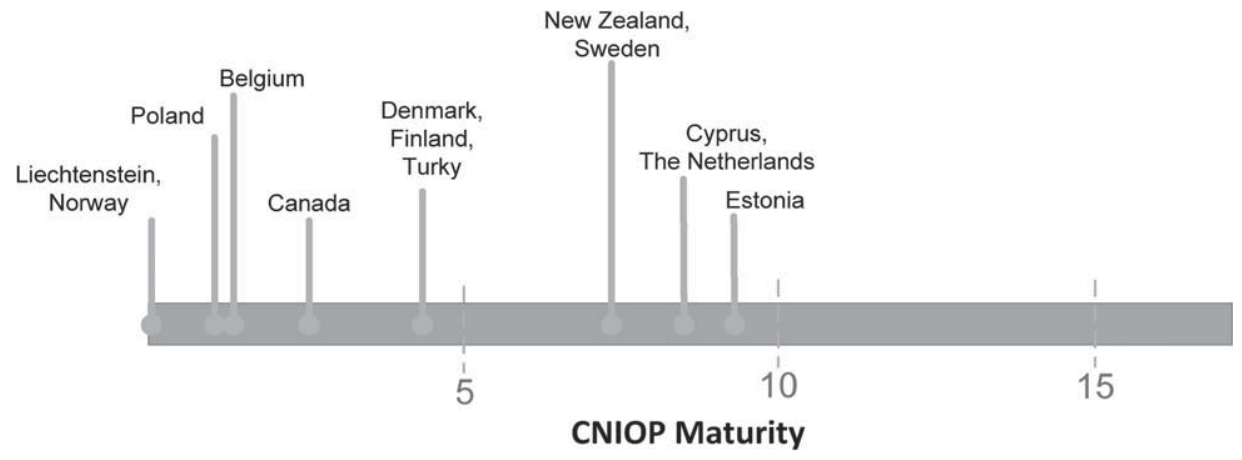

Fig. 9. The participating governments' cross-national interoperability maturity levels. 
in level 2, before they will be able to move the collaboration to the value-adding level, they all need to initialise the goal realisation and start calculating the cost and benefits for accomplishing the capabilities of extensive value measure and the high degree of interoperability goal realisation. In doing so they will be capable of answering questions as "What is the return of investment for the cross-national interoperability collaboration". But before answering that question, all the participating governments have to put quite an effort into the measuring the cross-national interoperability collaborations.

\section{Relation between EA and Interoperability Activities and Maturities}

Some respondents report to be having an EA program, national interoperability collaboration and cross-national interoperability collaboration, while others have neither. Table 4 shows the current activities of the respondents in the areas of EA, national interoperability and cross-national interoperability collaborations.

Five of the respondents, Denmark, Estonia, Finland, Netherlands and New Zealand, report to have activities in all three areas. Belgium is having national interoperability collaboration, and is planning a national EA program to be launched within three years and cross-national interoperability collaboration to be launched within two years. Canada and Cyprus are both having a national EA program and plans to launch both national interoperability and cross-national interoperability collaboration within two years. Lichtenstein has neither an EA program nor any of the interoperability collaborations, and reports no plans on launching any of them. Norway has no activity in any of the areas, and reports no plans on launching any. Poland reports to have an EA program and national interoperability collaboration, but no plans of launching cross-national interoperability collaboration.

Table 4

Summary of EA and interoperability activities

\begin{tabular}{lccc}
\hline Country & National EA program & National interoperability & Cross-national interoperability \\
\hline Belgium & (3 years) & $\mathrm{X}$ & $(2$ years) \\
Canada & $\mathrm{X}$ & $(2$ years) & (2 years) \\
Cyprus & $\mathrm{X}$ & $(2$ years) & $(2$ years) \\
Denmark & $\mathrm{X}$ & $\mathrm{X}$ & $\mathrm{X}$ \\
Estonia & $\mathrm{X}$ & $\mathrm{X}$ & $\mathrm{X}$ \\
Finland & $\mathrm{X}$ & $\mathrm{X}$ & $\mathrm{X}$ \\
Liechtenstein & (no plans) & (no plans) & (no plans) \\
Netherlands & $\mathrm{X}$ & $\mathrm{X}$ & $\mathrm{X}$ \\
New Zealand & $\mathrm{X}$ & $\mathrm{X}$ & $\mathrm{X}$ \\
Norway & (no plans) & $\mathrm{N} / \mathrm{A}$ & N/A \\
Poland & $\mathrm{X}$ & $\mathrm{X}$ & (no plans) \\
Sweden & (no plans) & $\mathrm{X}$ & $\mathrm{X}$ \\
Turkey & (1 year) & $\mathrm{X}$ & $\mathrm{X}$ \\
\hline
\end{tabular}


Sweden has no plans of a national EA program but has both national interoperability and cross-national interoperability collaborations. Turkey plans to launch a national EA program within a year but has both a national interoperability and cross-national interoperability collaboration.

The findings above lead to the conclusion that the respondents engaging in crossnational interoperability collaborations have either a national EA program or national interoperability collaboration, but in most cases both. This is also the case for the respondents planning to engage in cross-national interoperability collaboration.

The levels of maturity in the areas of EA and interoperability seem to be correlated for some of the governments. The Table 5 shows the achieved levels of maturity in the area of EA and interoperability for the participating governments.

Denmark, Estonia, Finland, Netherlands and New Zealand have achieved level 2 in their national EA program, national interoperability and cross-national interoperability collaboration. Canada, Cyprus and Poland have all achieved a higher level of EA program maturity than national interoperability collaboration maturity. This is reported to be due to the national interoperability collaborations are only in the establishment phase. Belgium, Sweden and Turkey are scoring higher in national interoperability maturity areas, as they only have those collaborations in operation. Belgium and Turkey have plans of establishing national EA programs, while Sweden has no plans concerning a national EA program.

The EA maturity levels for most of the governments are showing that they are in the operation phase. The same goes for national interoperability and cross-national interoperability collaborations. The relation between the interoperability and EA maturity is that none of the respondents have achieved a higher level in the cross-national interoperability collaboration maturity then in either the national EA program or the national interoperability collaboration.

Table 5

Summary of EA and interoperability maturity

\begin{tabular}{lccc}
\hline Country & National EA program & National interoperability & Cross-national interoperability \\
\hline Belgium & 1 & 2 & 1 \\
Canada & 2 & 1 & 1 \\
Cyprus & 3 & 1 & 2 \\
Denmark & 2 & 2 & 2 \\
Estonia & 2 & 2 & 2 \\
Finland & 2 & 2 & 2 \\
Liechtenstein & 1 & 0 & 0 \\
Netherlands & 2 & 2 & 2 \\
New Zealand & 2 & 2 & 2 \\
Norway & 0 & 0 & 0 \\
Poland & 2 & 1 & 0 \\
Sweden & 1 & 2 & 2 \\
Turkey & 1 & 2 & 2 \\
\hline
\end{tabular}


Only one of the national EA programs is placed at the value adding level, namely Cyprus. In order to get to that level and beyond there are several issues that has to be resolved. The issues that have to be resolved will be described in the following section.

The most pertaining issue to the low maturity of either EA programs or interoperability collaborations is the lack of performance measurement of the initiatives. Measurement of EA performance is only conducted by $17 \%$ of the governments, of which only $50 \%$ is calculating the cost of the EA program. The measurement is thereby only partial, as the KPI used to perform the measurement does not include the benefits gained from EA or the ROI. Additionally there is no measurement of EA maturity or status at a national level for any governments, which is further pinpointed by the fact that $37 \%$ of the respondents report that they do not know how much of the business, information and technical architectures is described and up to date. For application architecture the figure is $45 \%$. The same trend shows, when the focus turns to the maturity and status of cross-national interoperability collaborations. Cross-national interoperability collaboration performance measurement is not conducted by any governments. Not a single government is measuring the cost, benefit or ROI. The interoperability status itself isn't measured by any government either, which should be a vital part of the interoperability collaboration. All the governments have stated a lot of drivers for their EA programs or interoperability collaborations. It is alarming that only $66 \%$ of the governments have clearly stated qualitative goals, and only $50 \%$ have stated quantitative goals relating to their EA programs. The same trend shows when the focus turns to interoperability collaborations, where only $44 \%$ of the governments have qualitative goals and $22 \%$ quantitative goals related to the cross-national interoperability collaboration. This gets even worse as some governments has not stated the goals themselves and report that they do not even know if the goals have been achieved.

One could argue that the reported barriers are the reason for not achieving the goals of the EA programs or interoperability collaborations or even establishing them. Let us disregard the absence of goals for a while and take a look on the barriers for achieving them and the barriers for establishing a way to achieve them, through an EA program or interoperability collaboration. In the following the barriers for EA programs and interoperability collaborations will be combined to rank the barriers.

As Table 6 shows the two highest scoring barriers for establishing are either an EA program or interoperability collaboration the lack of skilled staff and top management support. Cultural barriers is ranked 3, funding 4, political and legal barriers 5 and the lack of proper guidelines 7. Skilled staff is a resource that is hard to neglect and in the fields of EA and interoperability are they a scarce resource. The competition for skilled staff is a key issue in the entire ICT industry, and not only in the public sector. The second most important barrier is the lack of top management support, which has a negative effect on some of the other barriers, such as funding, lack of skilled staff and cultural barriers. Without the support of top management it is impossible to get the needed funding and the legitimacy that might be needed to overcome the cultural barriers, there might be, for establishing EA program or interoperability collaboration. Without the necessary funding it is difficult to do anything and especially get the skilled staffs that are necessary to establish and run an EA program or interoperability collaboration. 
Table 6

Barriers for establishment of EA program, national interoperability (NIOP) and cross-national interoperability (CNIOP) collaboration

\begin{tabular}{llllll}
\hline Barriers for establishing: & EA & NIOP & CNIOP & Sum & Rank \\
\hline Lack of skilled staff & 34 & 19 & 21 & 74 & 1 \\
Lack of top management support & 37 & 17 & 19 & 73 & 2 \\
Cultural barriers & 26 & 19 & 20 & 65 & 3 \\
Funding & 27 & 14 & 17 & 58 & 4 \\
Political barriers & 22 & 13 & 22 & 57 & 5 \\
Legal barriers & 22 & 18 & 17 & 57 & 5 \\
Lack of proper guidelines & 20 & 10 & 17 & 47 & 7 \\
\hline
\end{tabular}

As Table 7 shows cultural barriers are perceived as the biggest barriers in achieving goals, closely followed by lack of skilled staff and top management support. Those barriers and their interrelation need no further explanation, as they were presented just above. Legal and political barriers can also be linked to top management support as many of the actions in the public sector are based on politics and regulated by law. Considering the politicians as the top management and ensuring their support will pave the way for breaking down the political and legal barriers EA programs and interoperability collaborations are facing. Lack of proper guidelines is seen as a minor barrier for both establishment and goal realization of EA programs and interoperability collaborations compared to the top barriers. This barrier is partly related to the lack of skilled staff barrier mentioned above and to the formal base of the guidelines, which will be dealt with separately.

It seems like lack of top management support must be dealt with quickly in order to overcome the other barriers, such as funding, lack of skilled staff and cultural barriers. What is it that the management likes, could be the question that needs to be answered before the EA programs and interoperability collaborations can move on to the value adding phases. The answer lies in the value adding phase itself. Management likes the sweet smell of success, but when the EA programs and interoperability collaborations do so little to provide the success's that the management like so much, it is really hard to get their attention, not to mention their support.

Table 7

Barriers for achieving goals of EA program and cross-national interoperability collaboration

\begin{tabular}{lcccc}
\hline Barrier for achieving goals of: & EA & Cross-national interoperability & Sum & Rank \\
\hline Cultural barriers & 35 & 23 & 58 & 1 \\
Lack of skilled staff & 40 & 14 & 54 & 2 \\
Lack of top management support & 36 & 17 & 53 & 3 \\
Legal barriers & 26 & 23 & 49 & 4 \\
Political barriers & 25 & 20 & 45 & 5 \\
Funding & 27 & 16 & 43 & 6 \\
Lack of proper guidelines & 27 & 11 & 38 & 7 \\
\hline
\end{tabular}


Having stated a lot of business driver for their activities in the areas of EA and interoperability it would be appropriate to conceptualise them, as achievable goals and start delivering the successes. The business drivers for EA programs and cross-national interoperability collaborations are shown in Table 8, both separately and accumulated.

The above stated business drivers can be converted to measurable goals in order to measure the performance of the EA programs and interoperability collaborations. The performance should be measured for many reasons including justifying the raison d'être of the undertakings. By measuring performance and achieving goals it will be more transparent what value the programs have for the governments. Cross-governmental interoperability can be measured by applying an interoperability framework capable of measuring interoperability status maturity. Furthermore many of the above stated business drivers can be categorised as goals in both the qualitative and quantitative categories. The evaluation of the goals can be performed through the use of terms like efficacy, efficiency, effectiveness, ethicality and elegance known as the five E's in Soft System Methodology (SSM) and relating to the overall performance of the system and the transformation executed (Checkland and Scholes, 1990).

- E1 - efficacy (are we doing it, is the transformation effected?),

- E2 - efficiency (the output achieved compared to the resources used to achieve it),

- E3 - effectiveness (is the longer term goal achieved by doing it?),

- E4 - ethicality (is the transformation morally sound?),

- E5 - elegance (is this an aesthetically pleasing transformation?).

The three first E's are the core performance measures of SSM and often supplemented by two E's, ethicality and elegance, of which ethicality can have great value for the public sector in order to evaluate if the transformation performed is morally sound. Applying the concepts of the five E's to the programs as a whole and to the lower level business drivers,

Table 8

Business drivers for EA programs and cross-national interoperability collaborations

\begin{tabular}{|c|c|c|c|c|}
\hline Business driver & EA & Cross-national interoperability & Score & Rank \\
\hline Cross-governmental interoperability & 56 & 38 & 94 & 1 \\
\hline Improve service delivery & 50 & 40 & 90 & 2 \\
\hline Support and enable business change & 48 & 32 & 80 & 3 \\
\hline Enable greater flexibility in business processes & 47 & 31 & 78 & 4 \\
\hline Improve process effectiveness & 40 & 37 & 77 & 5 \\
\hline Better align business and IT organisations & 51 & 25 & 76 & 6 \\
\hline Reduce time to deliver IT projects & 40 & 22 & 62 & 7 \\
\hline Reduce IT cost & 40 & 16 & 56 & 8 \\
\hline Infrastructure renewal & 32 & 15 & 47 & 9 \\
\hline Legacy transformation & 31 & 16 & 47 & 9 \\
\hline Enable outsourcing & 29 & 15 & 44 & 11 \\
\hline Resource management & 28 & 14 & 42 & 12 \\
\hline
\end{tabular}


can provide some of the needed performance measurement. Improving service delivery may result in a qualitative goal concerning the citizens, businesses or administrations experienced level of service, if it is external evaluation the governments are seeking. In the case of service delivery efficacy can be used to express whether services are delivered, efficiency can be used to express the output compared to the amount of resources used, and effectiveness can be used to express whether the right services were delivered in order to achieve the long term goals of the government.

\section{Conclusions}

The vision of e-government is stated to be the use of ICT within government to achieve more efficient operations, better quality of service and easy public access to government information and services. The e-government models pinpoints that an important precursor for realising the e-government vision is the integration of information systems. The integration of information systems is divided in a vertical and a horizontal integration and described as a very complex activity that requires cross agency collaboration among others. We have investigated the use of EA programs and interoperability collaborations as possible ways to create the needed integrations, both nationally and cross nationally.

The objective of the survey has been to analyse a comprehensive array of governments' cross-national interoperability collaboration activities in the governmental domain in an international perspective, for in this way to be able to measure the maturity levels of the collaborations.

We have found that national Enterprise Architecture programs and national interoperability collaborations serve as important precursors for engaging in cross-national interoperability collaborations. All the nations having a cross-national interoperability collaboration categorised in one maturity level have either a national Enterprise Architecture program or national interoperability collaboration categorised in at least the same maturity level, and none of the cross-national interoperability collaborations have a higher maturity level than the maturity levels of national activities.

The analysis pinpointed that the lack of top management support and the political barriers were major obstacles for the cross-national interoperability collaborations. This is a highly relevant area of further research especially in the light of the context the cross-national interoperability collaborations operate in. By delimiting the research from investigating the political aspects there are crucial areas left untouched. The impact of the political influence on the nations' collaborations can be categorised into a bipartition, one partition containing the member nations of EU and another partition containing everyone else. The rationale for such a division is that nations placed inside the EU may have one set of drivers for establishing the cross-national interoperability collaborations, while nations placed outside the EU may have another set of drivers. For the EU member states the collaborations are policy driven by the implementation of the Internal Market (the free flow of workers, goods and services, etc.), and supported by the IDABC program. In the case of the activities outside the EU it is believed that the initialisations of the 
cross-national interoperability collaborations are based on clear operational needs, which are not policy based the same way as in the EU. Though, based on the collected data it is not possible to verify the claim, and it should therefore be exposed for further investigation in order to determine what implication, it has for the cross-national interoperability collaborations.

Additionally, an interesting area for further investigation is the solutions adopted by the governments for achieving cross-national interoperability in the collaborations in different policy areas. In a multi-actor environment, as the governments acts in, the way of collaborations achieves cross-national interoperability could be done via different solutions according to whether the governments adopts individual solutions to each of the exchange partners, or adopts a common set of reference. The first way will lead to unilateral and bilateral solutions, while the latter will lead to multilateral solutions. In relation to the above stated bipartition of the nations' collaborations, another claim is that the benefits of being a nation in EU may be that multilateral solutions may be constructed easier, than for the collaborations of the nations placed outside EU. Being a member of the EU, and thereby be recommended to use the EIF as the framework for cross-national interoperability collaborations, expects to provoke multilateral solutions, but this has to be investigated, as the cross-national interoperability collaborations have to be consisting of more than two entities before the solutions will be multilateral.

For measuring the maturity levels, we have presented a range of EA maturity frameworks and applied one to the survey results. Likewise we have presented a range of interoperability frameworks and through a synthesis identified a possible way of measuring actual interoperability between entities, and finally placed the interoperability collaborations into a wider context and produced an interoperability collaboration maturity model. This model has been tested and produced the findings, and thereby it has proved its worth as a usable model. Even so, the maturity model may be exposed for further research and development for ensuring the adaption of ongoing progression of activities within crossnational interoperability collaborations.

\section{References}

Andersen, K. V. (2006). Management of e-government: Assessment of cost-benefit. Electronic Journal of eGovernment.

Andersen, K.V., Henriksen, H.Z. (2006). E-government maturity models: Extension of the layne and lee model. Government Information Quarterly, 23(2), 236-248.

Bernard, S.A. (2005). An Introduction to Enterprise Architecture, 2nd edition. AuthorHouse, Bloomington, Indiana.

Box, R.C. (1999). Running government like a business - Implications for public administration theory and practice. American Review of Public Administration, 29(1), 19-43.

Cap Gemini (2005). Online availability of public services: How does Europe progress? Web based survey on electronic public services. Available at:

http: / / ec.europa.eu/information_society/eeurope/2005/doc/all_about/ cgey4_measurement_final.pdf.

Checkland, P., Scholes, J. (1990). Soft Systems Methodology in Action. New York, Wiley.

Christiansen, P.E. (2006). International Enterprise Architecture Survey: Trends in Governmental Enterprise Architecture on a National Level. Master thesis. IT University of Copenhagen. Available at: http: / / easurvey.org/academicreport.htm. 
Doucet, G., Gøtze, J., Saha, P., Bernard, S. (2008). Coherency management: Using enterprise architecture for alignment, agility, and assurance. Journal of Enterprise Architecture, 4(2).

Dunleavy, P., Margetts, H., Bastow, S., Tinkler, J. (2006). New public management is dead - long live digital-era governance. Journal of Public Administration Research and Theory, 16(3), 467-494.

EIF (2004). European Interoperability Framework.

http: / / ec . europa. eu/idabc/en/document/7641/6014.

Fountain, J.E. (2001). Paradoxes of public sector customer services. Governance, 14(1).

GAO (2003). Information Technology. A Rramework for Assessing and Improving Enterprise Architecture Management (Version 1.1) GAO-03-584G.

GAO (2006). Enterprise Architecture, Leadership Remains Key to Establishing and Leveraging Architectures for Organizational Transformation. Available at: http: / / www.gao.gov/new. items / d06831.paf.

Gartner Group (2007). Preparation for Update European Interoperability Framework 2.0 - final report. http: / / ec . europa . eu/idabc/servlets / Doc? id=31505.

Grant, G., Chau, D. (2005). Developing a generic framework for e-government. Journal of Global Information Management, 13(1), 1-30.

Gøtze, J., Christiansen, P.E. (2007). Trends in governmental enterprise architecture: Reviewing national EA programs - Part 1. Journal of Enterprise Architecture, 3(1)

Gøtze, J., Östberg, O. (2007). Interoperability, Change, and Architecture. ICA Study Group on Enterprise Architecture in Government. International Council for Information Technology in Government Administration. Available at: www.ica-it.org/studygroups/ICA_SG_2007.pdf.

Heeks, R. (2006). Understanding and measuring egovernment: International benchmarking studies. In: $E$ Participation and E-Government: Understanding the Present and Creating the Future, Budapest, Hungary, 27-28 July 2006

Herzum, P. (2003). Applying enterprise architecture: Cutter consortium. Enterprise Architecture, 6(3).

Hirschheim, R., Klein, H. (1989). Four paradigms of information systems development. Communications of the ACM, 32(10).

Hjort-Madsen, K. (2006). Enterprise Architecture Implementation and Management: A Case Study on Interoperability. IT-University of Copenhagen, 2006.

Hjort-Madsen, K., Gøtze, J. (2004). Enterprise Architecture in Government-Towards a Multi-Level Framework for Managing IT in Government.

Industry Advisory Council (IAC) and Enterprise Architecture SIG. (2003). Business Line Architecture \& Integration. Washington, DC.

King, J.L., Kraemer, K.L. (2003). E-Government: Will the Time after Be Any Different? Center for Research on IT and Organizations, University of California, Irvine.

Klischewski, R. (2004). Information integration or process integration? How to achieve interoperability in administration. In: EGOV 2004, pp. 57-65.

Layne, K., Lee, J. (2001). Developing fully functional e-government: A four stage model. Government Information Quarterly, 18, 122-136.

Mortensen, R., Paszkowski, S. (2008). Cross-National Interoperability Survey: Trends in governmental CrossNational Interoperability Collaborations. Master Thesis. Copenhagen Business School.

Office of Management and Budget (2005). Federal Enterprise Architecture Program EA Assessment Framework 2.0, December 2005.

Office of Management and Budget (2007). Federal Enterprise Architecture Program EA Assessment Framework 2.2 , October 2007

Park, J., Ram, S. (2004) Information systems interoperability: What lies beneath? ACM Transactions on Information Systems, 22(4).

Peristeras, V., Tarabanis, K. (2006). The connection, communication, consolidation, collaboration interoperability framework (C4IF) for information systems interoperability. IBIS - International Journal of Interoperability in Business Information Systems, 1(1), 61-72.

Schein, E.H. (1992). Organizational Culture and Leadership. Chichester, Jossey Bass Wiley.

Siau, K., Long, Y. (2005). Synthesizing e-government stage models - A meta-synthesis based on metaethnography approach. Industrial Management and Data Systems, 105(4), 443-458.

Sowa and Zachman (1992). Extending and formalizing the framework for information systems architecture. IBM Systems Journal, 31(3) 
Tambouris et al. (2007). Study on Interoperability at Local and Regional Level. Center for Research and Technology Hellas Institute of Informatics and Telematics (CERTH/ITI), European Institute of Public Administration (EIPA) and Institut für Informationsmanagement Bremen GmbH. Available at: http: / / www. epractice.eu/resource/1309.

Zachman, J.A. (1999). Zachman on the Framework, ZIFA.

J. Gøtze has worked with government technology, enterprise architecture and open standards for more than 15 years. He is the president of alEA, the Association of Enterprise Architects. He is a co-founder of EA Fellows, a group of enterprise architecture professionals in Denmark. He is also a non-tenured associate professor at Copenhagen Business School and at the Danish IT University. He holds a master of science degree in engineering and a PhD in participatory design, both from the Technical University of Denmark.

P.E. Christiansen has worked within the field of IT architecture and enterprise architecture the last 8 years. Today he is employed as a senior consultant at Deloitte Business Consulting advising both the public sector and privately held companies. Peter is also a teaching assistant at Copenhagen Business School. Prior to joining Deloitte, Peter worked with EA in the Danish Central Customs and Tax Administration, the Digital Taskforce and in the National IT and Telecom Agency. He holds a master of science degree in information technology from the IT University of Copenhagen.

R.K. Mortensen received the BS and MS degrees in computer science and business administration from Copenhagen Business School in 2003 and 2008, respectively. He is currently working as a senior consultant in a Danish Software Developing Company focusing in integrations of critical business systems. His research interests include among others interoperability, enterprise architecture, system development and implementation, change management and knowledge management.

S. Paszkowski received the BS and MS degrees in computer science and business administration from Copenhagen Business School in 2004 and 2008, respectively. He is currently working as an enterprise architect in a multinational software developing company. His research interests include interoperability, system integration, change management, software engineering, and P2P networks.

\section{Tarpvalstybiniai duomenu mainai ir organizacijų integruotu informaciniu sistemu architektūra}

John GØTZE, Peter Engelund CHRISTIANSEN, Rasmus Kirkegaard MORTENSEN, Slawomir PASZKOWSKI

DuomenųU mainai tampa vis svarbesni tiek valstybių viduje, tiek ir tarp skirtingose valstybėse esančiu organizaciju. Straipsnyje analizuojama ir vertinama 13 valstybių vyriausybinio sektoriaus organizaciju tarpvalstybinių duomenų mainų procesu branda. Ši analizė apima valstybinių organizacijų integruotų informacinių sistemų architektūrų ir nacionalinio lygmens duomenų mainų procesu analizę. Vertinama, ar esamos architektūros ir procesai yra taip suprojektuoti, kad jie galètu peraugti ị tarpvalstybinius duomenų mainų procesus. Išnagrinètos nacionalinio lygmens ir tarpvalstybinių duomenų mainų procesų brandos priklausomybès. 